Gut, 1973, 14, 221-232

\title{
The nature of the copper complexes in bile and their relationship to the absorption and excretion of copper in normal subjects and in Wilson's disease
}

\author{
K. O. LEWIS \\ From the Department of Chemical Pathology, Medical School, University of Leeds
}

SUMMARY Copper in bile has been shown by electrophoresis to occur neither as free ions nor complexed to protein but to be associated with a component of the micellar complexes of bile. Solvent fractionation studies suggest that the bile salt components of the lecithin-bile salt complexes are the active binding agents. The effects of specific bile salts on the behaviour of copper during electrophoresis supports this possibility.

The relationship of certain bile salts to the excretion of copper in man during the time that an external biliary fistula was functioning and to the intestinal absorption of copper in the rat was found to confirm this concept.

The results show that copper in bile is associated with taurochenodeoxycholate and suggest an explanation for the elevated tissue copper levels found in Wilson's disease.

Ionic copper is extremely toxic, probably exerting its effect by binding to membrane ATP-ase and hence inhibiting ion transport (Peters, 1966). Physiological mechanisms must exist, however, which enable copper to pass through biological membranes during its absorption, distribution, and secretion into the bile. In view of the strong tendency of copper to form chelates it seems likely that it is transported in complexed form. Information on this point might be important for our understanding of diseases characterized by a failure to mobilize copper from the tissues. The major route for the excretion of copper is via the bile and faeces, and so a study has been made of the nature of the copper complexes in bile. The only data available on biliary copper at the commencement of this study were that following intravenous injection of ${ }^{64} \mathrm{Cu}$-labelled cupric acetate about $40 \%$ of copper in rat bile is not dialysable, but with the passage of time, a progressively larger proportion of ${ }^{64} \mathrm{Cu}$ excreted in the bile is not dialysable and precipitable with trichloracetic acid (Farrer and Mistilis, 1968). These results were considered to be consistent with the hypothesis that bile contains a protein to which copper is strongly

${ }^{1}$ Present address: Department of Biochemistry, University of Zambia, PO Box 2379, Lusaka, Zambia.

Received for publication 13 December 1972. bound. Evidence is presented in this paper that this is unlikely and that copper in bile is bound to low molecular weight compounds.

\section{Materials}

Human hepatic bile was collected via a $T$ tube after cholecystectomy. Gallbladder bile was obtained at necropsy. Bile was collected from albino Wistar rats by cannulation of the bile duct (Weinbren and Billing, 1953). Specimens for electrophoresis were lyophilized at $35^{\circ}$ in vacuo by rotary evaporation and the dry weight was determined.

The timed collection of $T$ tube bile was made with an LKB fraction collector using a sterilized dropping chamber (fig. 1) from a female patient ( $45 \mathrm{yr}$ ) after cholecystectomy. Collection was started two hr after the fistula had been fashioned. Fractions were taken each quarter of an hour for $24 \mathrm{hr}$ and their volume was recorded.

Specimens of duodenal juice were obtained by duodenal aspiration following the administration of pancreozymin (Boots Pure Drug Co Ltd, Nottingham).

Egg lecithin, ox-bile sodium taurocholate, purified bile acids, and bile salts and Russell's viper venom were purchased from the Sigma Chemical Co. 


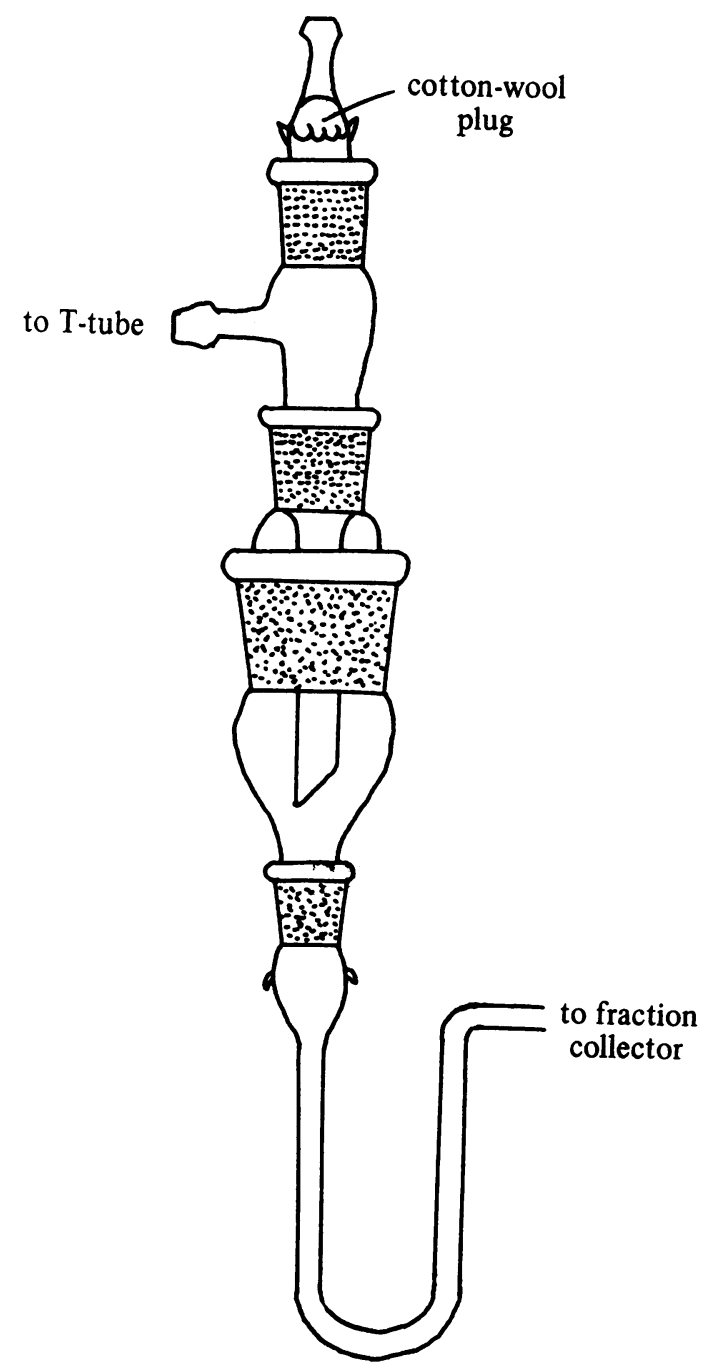

Fig. 1 Sterilizable dropping chamber. Bile could be collected in the fraction collector with no chance of airborne bacteria infecting the common bile duct.

\section{Analytical Methods}

SYNTHETIC BILE SALT-LECITHIN COMPLEXES Bile salt $(32 \mathrm{mg})$, lecithin $(10 \mathrm{mg})$, and cholesterol (4 $\mathrm{mg})$ were rubbed together until the crumbling mass took on a waxy consistency. The addition of water $(2.5 \mathrm{ml})$ or an aqueous buffer solution resulted in complete solution.

\section{ANALYTICAL SOLVENT FRACTIONATION OF LYOPHILIZED BILE}

Bile solids were extracted by the series of solventspetroleum ether $\left(40-60^{\circ}\right)$, chloroform, chloroformmethanol $(1: 1 \mathrm{v} / \mathrm{v})$, methanol, and finally water. In a typical experiment, the material $(180 \mathrm{mg})$ was boiled with peiroleum ether $(20 \mathrm{ml})$ for three minutes and the supernatant was separated. The residue was reextracted with petroleum ether $(20 \mathrm{ml})$, the supernatants were combined, and the cycle was repeated with the next solvent. Extracts were evaporated and copper was determined colorimetrically following perchloric acid digestion (Stoner and Dasler, 1960).

\section{PREPARATIVE SOLVENT FRACTIONATION OF LYOPHILIZED BILE}

Solvent fractionation and crystallization were used to separate the components of bile solids, the details of which are shown in Table II. Copper was monitored during the fractionation. Submilligram amounts of fractions were spotted onto thin-layer chromatography (tlc) plates (Merck, Silica gel precoated on glass), organic material was combusted with a Bunsen flame, then the plates were sprayed with 1,5-diphenylcarbohydrazide-saturated chloroform. Copper gave a red colour. Combustion could often be dispensed with; the organic materials were then removed by developing the thin-layer chromatography plate with chloroform-methanol-water $(65: 25: 4)$ and copper remained at the origin.

PHOSPHOLIPASE A TREATMENT OF THE CHLOROFORM EXTRACT OF LYOPHILIZED BILE (TABLE II)

The residue $(367 \mathrm{mg}$ ) was taken up in ether $(5 \mathrm{ml})$,

\begin{tabular}{|c|c|c|c|c|c|c|}
\hline Bile No. & $\begin{array}{l}\rightarrow \text { Solvent } \text { No. } 1 \\
\text { Petroleum }\left(40-60^{\circ}\right) \\
\downarrow\end{array}$ & $\begin{array}{l}\rightarrow \text { Solvent No. } 2 \\
\underset{\downarrow}{\mathrm{CHCl}}\end{array}$ & $\begin{array}{l}\rightarrow \text { Solvent } \mathrm{No}^{3} \\
\mathrm{MeOH}-\mathrm{CHCl}_{3} \\
\quad \downarrow\end{array}$ & $\begin{array}{l}\rightarrow \text { Solvent No. } 4 \\
\text { MeOH } \\
\quad \downarrow\end{array}$ & $\longrightarrow$ Wolvent No. 5 - & $\underset{\downarrow}{\text { Residue }}$ \\
\hline $\begin{array}{l}1 \text { human } \\
2 \text { (human) } \\
3 \text { (human) } \\
4 \text { (rat) }\end{array}$ & $\begin{array}{l}2 \cdot 8 \\
5 \cdot 8 \\
5 \cdot 2 \\
3.0\end{array}$ & $\begin{array}{l}25 \cdot 2 \\
13 \cdot 3 \\
27 \cdot 8 \\
-\end{array}$ & $\begin{array}{l}32 \cdot 6 \\
15 \cdot 2 \\
21 \cdot 6 \\
28 \cdot 4\end{array}$ & $\begin{array}{l}19 \cdot 2 \\
25 \cdot 3 \\
10 \cdot 3 \\
48 \cdot 6\end{array}$ & $\begin{array}{r}0.0 \\
0.0 \\
0.0 \\
20.0\end{array}$ & $\begin{array}{r}20 \cdot 2 \\
40 \cdot 4 \\
35 \cdot 1 \\
0 \cdot 0\end{array}$ \\
\hline
\end{tabular}

Table I Percentage of copper extracted from lyophilized bile into a series of solvents of increasing polarity 
shaken with just sufficient water to form an emulsion, and Russell's viper venom $(1.0 \mathrm{mg})$ added. The mixture was incubated at room temperature overnight then evaporated in vacuo. The residue was extracted with ether, in which both lysolecithin and bile salts are insoluble, then both residue and ethereal extract were examined for copper. All the copper had become ether insoluble.

\section{THIN-LAYER CHROMATOGRAPHY}

\section{Bile salts}

Silica gel, BuOH-AcOH-H $\left.\mathrm{H}_{2} \mathrm{O}(10: 1) 1 \mathrm{v} / \mathrm{v}\right)$ or EtOAc-EtOH-NH $\mathrm{N}_{4} \mathrm{OH}(35: 40: 25 \mathrm{v} / \mathrm{v})$, detected by anisaldehyde $(0.5 \mathrm{ml})$ and $\mathrm{H}_{2} \mathrm{SO}_{4}(1.0 \mathrm{ml})$ in glacial acetic acid $(50 \mathrm{ml})$ was followed by heating at $110^{\circ}$ for 10 minutes. Duodenal juice was applied directly to the tlc plate, but bile was first diluted with 4 volumes of water. Bile salt concentrations differed widely from one duodenal juice to another due to the collection technique and rate of bile production. No attempt was made to measure absolute levels of bile sa ts in specimens; the tlc technique was used to compare the relative proportions of the different bile salts in each specimen (separation as in Fig. 4). To assist visual comparison of patterns from different subjects, the quantity of specimen applied to the chromatogram $(2-10 \mu l)$ was adjusted to give the same intensity for the glycocholate spot in each of the 18 cases studied.

\section{Bile acids}

Silica gel, iso-octane-di-isopropyl ether-acetic acid $(50: 25: 25 \mathrm{v} / \mathrm{v})$, was detected with the anisaldehyde reagent. Duodenal juice or bile was subjected to alkaline hydrolysis under standard conditions (Bergström and Sjöval, 1954) and the free bile acids were extracted by petroleum ether from the acidified solution. The extracts were subjected to tlc and the bile acids visualized with the anisaldehyde reagent.

\section{ELECTROPHORESIS}

A $2 \%$ aqueous solution of Ionagar (Oxoid Ltd, London) was diluted with an equal volume of buffer $\left(p \mathrm{H} \quad 6.0, \quad \mathrm{KH}_{2} \mathrm{PO}_{4} / \mathrm{Na}_{2}-\mathrm{HPO}_{4}, \mathrm{I}=0.2\right)$ and the mixture $(25 \mathrm{ml})$ applied to glass plates $(5 \times 20 \mathrm{~cm})$. Bile solids, etc $(5-15 \mathrm{mg})$, in buffer $(0 \cdot 1 \mathrm{ml})$ were placed in a groove in the agar gel and electrophoresed at $25 \mathrm{ma} /$ plate for two hours. Pairs of plates were run. One was stained for protein by immersion $(1 \%$ Amido Black in $7 \%$ aqueous acetic acid) followed by destaining in aqueous acetic acid $(7 \%)$ alone. The second plate was sliced into segments $(1.0 \mathrm{~cm})$ which were analysed for copper.

COPPER DETERMINATION ON GEL SLICES

The method was that of Stoner and Dasler (1960) with the modification that $15.0 \mathrm{ml}$ of saturated $\mathrm{N}_{3} \mathrm{PO}_{4}$ was used. Accuracy and precision were similar to the published values when the digestion time was not less than one hour. Slices containing up to $3 \mu \mathrm{g}$ of copper were digested with perchloric acid $(60 \%$ AristaR, BDH London, $2.0 \mathrm{ml})$ for one hour in Pyrex tubes $(2 \times 20 \mathrm{~cm})$. Saturated $\mathrm{Na}_{3} \mathrm{PO}_{4}$ was added $(15.0 \mathrm{ml})$ and the $p \mathrm{H}$ checked to be greater than 9.5 (solid $\mathrm{NaOH}$ was added if the $p \mathrm{H}$ was still less than this value). A benzene solution of 1,5diphenylcarbohydrazide $(0.01 \%, 7.0 \mathrm{ml})$ was added and the tubes were swirled mechanically for 30 seconds. The benzene layer was removed immediately and the OD $540 \mathrm{~nm}$ was read against the reagent blank. Blanks for the electrophoretogram segments consisted of segments $(1.0 \mathrm{~cm})$ from an unrun plate. Standards consisted of $1.0 \mu \mathrm{g}$ copper as copper sulphate added to tubes containing digested perchloric acid.

COPPER DETERMINATIONS ON WHOLE BILE Copper concentrations in rat bile and $\mathrm{T}$-tube bile were measured with the Perkin-Elmer 303 atomic absorption spectrometer. Specimens were diluted $\times 10$ with deionized water. Standards consisted of copper sulphate $(0 \cdot 1-8.0 \mu \mathrm{g} \mathrm{Cu} / \mathrm{ml})$ in deionized water. This method was not intended to yield absolute levels of copper. In the animal and human experiments there were large changes in copper concentration and this procedure was adequate to show the relative copper levels. Copper $(5 \mu \mathrm{g} / \mathrm{ml})$ in saline or saline containing sodium taurocholate $(3 \cdot 5-13.0 \mathrm{mg} / \mathrm{ml})$ gave identical readings.

IONIC COPPER DETERMINATIONS

Ionic copper was measured by a new technique (Walker, Dawson, and Ellis, 1969) which involves electrolysis of a biological fluid for 15 seconds at $150 \mu \mathrm{A} / 1.35 \mathrm{~V}$ using iridium wire electrodes $1.0 \mathrm{~cm}$ apart. Following deposition of copper on the cathode (approximately $10^{-11} \mathrm{~g}$ ), this electrode is introduced into a flame aligned with the optical system of an atomic absorption spectrometer set to measure the copper line at $324.7 \mathrm{~nm}$. The peak height obtained on a one-second response recorder is proportional to the concentration of copper and the system gives an adequate signal in the range $0.1 \mu \mathrm{g} / \mathrm{ml}$ to $1.0 \mu \mathrm{g} / \mathrm{ml}$ of copper in biological fluids (Dawson and Ellis, 1970).

OTHER DETERMINATIONS ON BILE Determinations of sodium, potassium, chloride, $\mathrm{CO}_{2}$-combining power, calcium, inorganic phosphate, urea, and uric acid were made with Technicon AutoAnalyzer methods for serum using whole bile. Total bile salt concentrations were calculated from the 
difference between the sums of the other anion and cation concentrations expressed as milliequivalents (Wheeler and Ramos, 1960). Phospholipid concentrations were obtained by measurement of total phosphorus in whole bile after perchloric acid digestion (Connerty, Briggs, and Eaton, 1961) followed by subtraction of the inorganic phosphate value.

COPPER 'EXTRACTABILITY' FROM BILE, SOLUTIONS OF BILE SALTS, AND SOLUTIONS OF LECITHIN-BILE SALT (LBS) COMPLEXES

Bile $(0.3 \mathrm{ml})$ was placed in $25 \mathrm{ml}$ tubes and enriched with copper if required by the addition of aqueous $\mathrm{CuSO}_{4}(0.1 \mathrm{ml}, 25 \mu \mathrm{g} \mathrm{Cu} / \mathrm{ml})$. Water $(4.0 \mathrm{ml})$ was added, followed by saturated $\mathrm{Na}_{3} \mathrm{PO}_{4}$ and 1,5diphenyl-carbohydrazide in benzene $(0.01 \%, 3.0 \mathrm{ml})$. The tube was swirled for 15 seconds then the organic layer removed immediately. The OD at $540 \mathrm{~nm}$ was read against a reagent blank (bile replaced by $0.3 \mathrm{ml}$ water); standards consisted of aqueous $\mathrm{CuSO}_{4}$. The procedure was also used on a series of bile acids and bile salts $(5.3 \mathrm{mg})$ in aqueous $\mathrm{CuSO}_{4}(0.1 \mathrm{ml}, 25 \mu \mathrm{g}$ $\mathrm{Cu} / \mathrm{ml})$. It was also used on a series of LBS complexes prepared from lecithin $(1.67 \mathrm{mg})$, bile salt $(5.3 \mathrm{mg})$, and cholesterol $(0.67 \mathrm{mg})$. Copper was added as aqueous $\mathrm{CuSO}_{4}(0 \cdot 1 \mathrm{ml}, 25 \mu \mathrm{g} \mathrm{Cu} / \mathrm{ml})$.

\section{Intestinal Absorption Experiments}

BILIARY COPPER AFTER INTRADUODENAL ADMINISTRATION OF COPPER AND BILE SALTS

Female Wister rats, 4-7 weeks old (body weight 170-210 g) were used. They had free access to food (commercial pellets) and water before an experiment. Animals were anaesthetized by an intraperitoneal injection of Nembutal and the bile duct was cannulated. The body wall was closed and bile collected for periods of 10 minutes. After 30 minutes the body was re-opened and an intraduodenal injection $(0.5 \mathrm{ml})$ administered slowly with the needle pointing along the gut. The injection flowed easily and it was not necessary to clamp the intestine above the injection point to prevent backward flow. After the body wall had been closed again bile was collected at 10-minute intervals for two hours. The following injections were used: (a) $500 \mu \mathrm{g} \mathrm{Cu}$ in physiological saline with a control of saline; (b) $500 \mu \mathrm{g} \mathrm{Cu}$ in human bile with a control of human bile; (c) $500 \mu \mathrm{g} \mathrm{Cu}+$ LBS complex in saline with the control consisting of LBS complex in saline. The bile used was a fresh postmortem specimen head injury from a case with no sign or history of liver disease. The LBS complex, prepared as previously described, was dissolved in $2.5 \mathrm{ml}$ of physiological saline containing $1000 \mu \mathrm{g}$ $\mathrm{Cu} / \mathrm{ml}$. Copper determinations on the rat bile were by AAS as previously described.

\section{Results}

\section{BEHAVIOUR OF COPPER IN BILE}

\section{Solvent fractionation}

The biliary copper complexes were studied by extraction of copper by a series of solvents of increasing polarity (Table I). A significant proportion of the copper was extracted in the chloroform, chloroform-methanol, and methanol fractions and there was also a proportion not extractable.

Extracts of dried bile were examined by tlc (Table II). The chloroform extract consisted mostly of lecithin, bile salts, and pigment. Solvent subfractionation was attempted but without success. The residue from this chloroform fraction was treated with phospholipase A and all the copper was then found to be insoluble in ether.

The chloroform-methanol extract of bile was next examined. The residue from the extract of one bile specimen, a much less pigmented specimen than the others, was readily subfractionated. A colourless

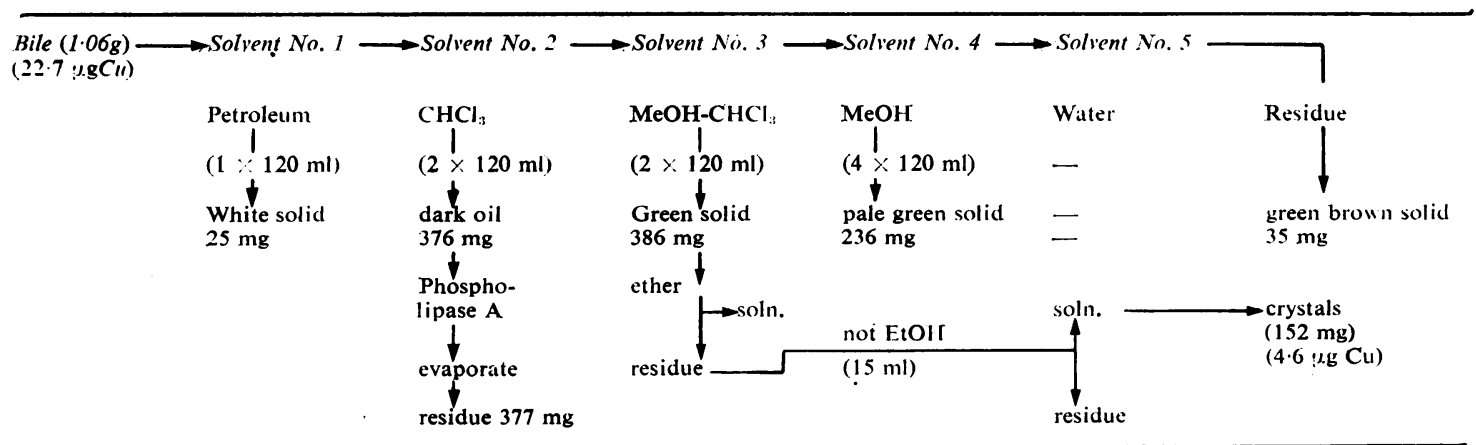

Table II Solvent extraction of a lyophilized bile by a series of solvents of increasing polarity 
copper-containing solid was crystallized out which tlc showed to be a mixture of bile salts. No other organic materials were detected on tlc with iodine or charring.

\section{Electrophoresis of bile}

Six specimens of human bile were examined. There were always two pigment bands present which moved between 50 and $60 \mathrm{~nm}$ towards the anode, the slower predominating in width. Figure $2 \mathrm{a}$ shows a typical example. Copper was always confined to the pigmented areas and in five cases this did not overlap the albumin band. In four specimens the pigment bands were quite sharp, and the copper was closely confined to them. There was no copper at the origin nor on the cathodic side of the origin. With pooled rat bile the albumin and pigmented bands also separated well; the pigment bands were very discrete and contained the whole of the biliary copper.

\begin{tabular}{llll}
\hline Bile No. & $\begin{array}{l}\text { Dry Weight } \\
(\mathrm{g} / \mathrm{l})\end{array}$ & $\begin{array}{l}\text { Copper } \\
(\mathrm{mg} / \mathrm{l})\end{array}$ & $\begin{array}{l}\text { Ratio of Copper } \\
\text { in Fast : Slow } \\
\text { Bands }\end{array}$ \\
\hline 1 & 17.2 & 0.27 & $1: 1.8$ \\
2 & 16.0 & 0.34 & $1: 2.0$ \\
3 & 18.1 & 1.92 & $1: 0.2$ \\
4 & 19.2 & 6.36 & $1: 1.5$ \\
5 & 14.6 & 0.50 & $1: 0.9$ \\
6 & 21.2 & 0.28 & $1: 0.2$ \\
Pooled rat bile & - & 0.42 & $1: 0.2$ \\
\hline
\end{tabular}

Table III Composition of bile specimens subjected to electrophoresis

A series of electrophoretic runs was made using mixtures of copper sulphate with various substances (Fig. 2). With aqueous copper sulphate in phosphate buffer $(p H$ 6.0) the copper remained at the origin as insoluble cupric phosphate. Electrophoresis of bile solids (15 mg) with $100 \mu \mathrm{g}$ of copper gave the usual pattern of protein and pigment bands and the copper was again confined to the pigmented bands, $90 \%$ appearing in the faster of these.

With crude taurocholate and copper sulphate $(10 \mu \mathrm{g} \mathrm{Cu}+12 \mathrm{mg}$ bile salt) the copper migrated only $20 \mathrm{~mm}$ towards the anode and tailed to the origin. A fast moving micellar band appeared in the case of crude taurocholate-lecithin-cholesterol containing added copper. The copper, while largely at the origin, was distributed all the way to the micellar band, about $20 \%$ being located at the band.

\section{Ionic copper}

A solution containing physiological levels of crude sodium taurocholate and copper sulphate $(1 \cdot 0 \mu \mathrm{g} / \mathrm{ml}$

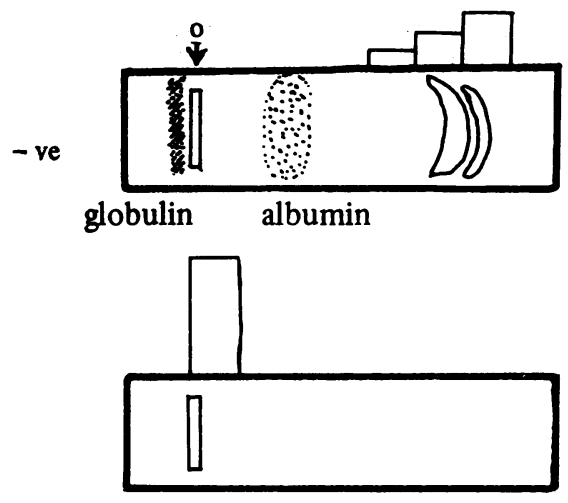

(a)

(b)

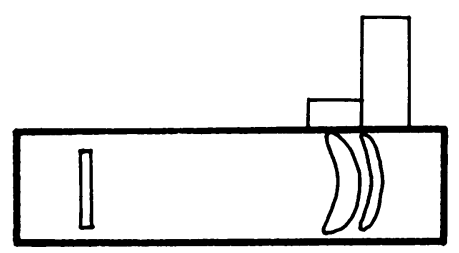

(c)

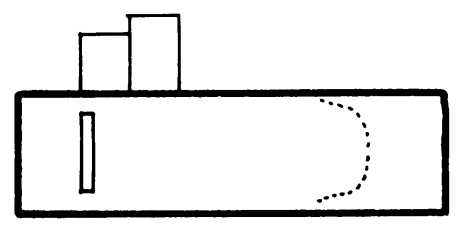

(d)

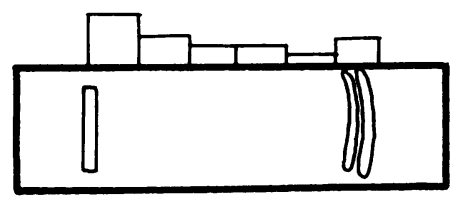

(e)

Fig. 2 Agar gel electrophoresis of bile and some bile constituents.

The position of the micellar bands is indicated and the distribution of copper is shown by the histogram alongside. The examples shown are: (a) bile; (b) $\mathrm{CuSO}_{4}$; (c) bile $+\mathrm{CuSO}_{4}$; (d) crude taurocholate $+\mathrm{CuSO}_{4}$;

(e) crude taurocholate + lecithin $+\mathrm{CuSO}_{4}$.

$\mathrm{Cu}, 10.0 \mathrm{mg} / \mathrm{ml}$ bile salt) behaved as bile in that no ionic copper could be detected. Dilute aqueous taurocholate containing copper $\left(1.57 \times 10^{-5}\right.$ molar with respect to both copper and taurocholate) showed a cupric ion concentration indistinguishable from pure aqueous copper sulphate $(1 \cdot 0 \mu \mathrm{g} / \mathrm{ml} \mathrm{Cu})$. 


\section{EXCRETION OF COPPER IN HUMAN BILE}

Biliary copper and bile salt levels in man estimated by means of a biliary fistula

The concentrations of biliary constituents at zero and $24 \mathrm{hr}$ are shown in Table IV and the intermediate values are shown in Fig. 3 as a percentage of the value at zero hours. There was a gradual fall in bile flow to $80 \%$ of the initial rate over seven hr after which it remained constant. The concentration of $\mathrm{K}^{+}, \mathrm{Cl}^{-}$, and $\mathrm{HCO}_{3}^{-}$remained fairly constant over the $24 \mathrm{hr}$ whereas the sodium concentration began to fall after seven hours.

The calculated bile salt concentration remained constant for seven $\mathrm{hr}$, fell gradually over $12 \mathrm{hr}$ to $60 \%$ of the initial value then increased slightly. Phospholipid concentration remained constant for six $\mathrm{hr}$ then over eight $\mathrm{hr}$ fell to $30 \%$, afterwards levelling off at $40 \%$.

Copper gradually fell over seven hr to $90 \%$ of the

\begin{tabular}{lcc}
\hline Constituent & \multicolumn{2}{c}{ Concentration } \\
\cline { 2 - 3 } & Initial & At 24 Hours \\
\hline $\mathrm{Na}$ & 153 & $139(\mathrm{~m}$-equiv/l) \\
$\mathrm{K}$ & $4 \cdot 7$ & $4.8(\mathrm{~m}$-equiv/l) \\
$\mathrm{Ca}$ & $11 \cdot 2$ & $9 \cdot 8(\mathrm{mg} / 100 \mathrm{ml})$ \\
$\mathrm{Cu}$ & 156 & $28(\mu \mathrm{g} / 100 \mathrm{ml})$ \\
$\mathrm{Cl}$ & 112 & $107(\mathrm{~m}-\mathrm{equiv} / \mathrm{l})$ \\
$\mathrm{CO}$-C.P. & 17 & $19(\mathrm{~m}$-equiv/l) \\
P(inorg.) & $2 \cdot 8$ & $2 \cdot 2(\mathrm{mg} / 100 \mathrm{ml})$ \\
Phospholipid & 580 & $213(\mathrm{mg} / 100 \mathrm{ml})$ \\
Urea & 30 & $23(\mathrm{mg} / 100 \mathrm{ml})$ \\
Uric acid & $6 \cdot 3$ & $7 \cdot 6(\mathrm{mg} / 100 \mathrm{ml})$ \\
Bile sals & 29 & $18(\mathrm{~m}$-equiv $/ \mathrm{l})$ \\
\hline
\end{tabular}

Table IV Initial and final concentrations of constituents of human T-tube bile initial concentration, followed by a precipitous drop to $30 \%$ over the next one and a half $\mathrm{hr}$, after which it levelled out at $20 \%$.

The concentrations of urea, calcium, and phosphate fell about $10 \%$ over the first seven hours then remained constant.

Thin-layer chromatography was used to examine the variation in composition of the fractions over the 24-hr period. The tlc system separated glycine conjugates from taurine conjugates and dihydroxy bile salts from the trihydroxy bile salts but did not resolve deoxycholic acid conjugates from chenodeoxycholic acid conjugates. The results are shown in Figure 4. Fractions $C$ and $D$ are those immediately before and following the point where copper levels changed considerably. The levels of the dihydroxy bile salts (glycine and taurine conjugates) fell dramatically and in parallel with the change in copper concentration, remaining low as did the copper.

INTERACTION OF COPPER AND BILE SALTS IN RATS

Copper extractability from bile, solutions of bile salts, and solutions of lecithin-bile salt complexes

Chelation-extraction experiments were carried out using copper-enriched bile and also bile acids, bile salts, and LBS complexes with added copper. The results, expressed as percentage recovery of copper, are shown in Table V. The capacity to inhibit the extraction of copper varied widely amongst the bile salts examined. Glycocholate and taurochenodeoxycholate (either free or as a lecithin complex) exhibited this effect to an extent comparable to that of bile.

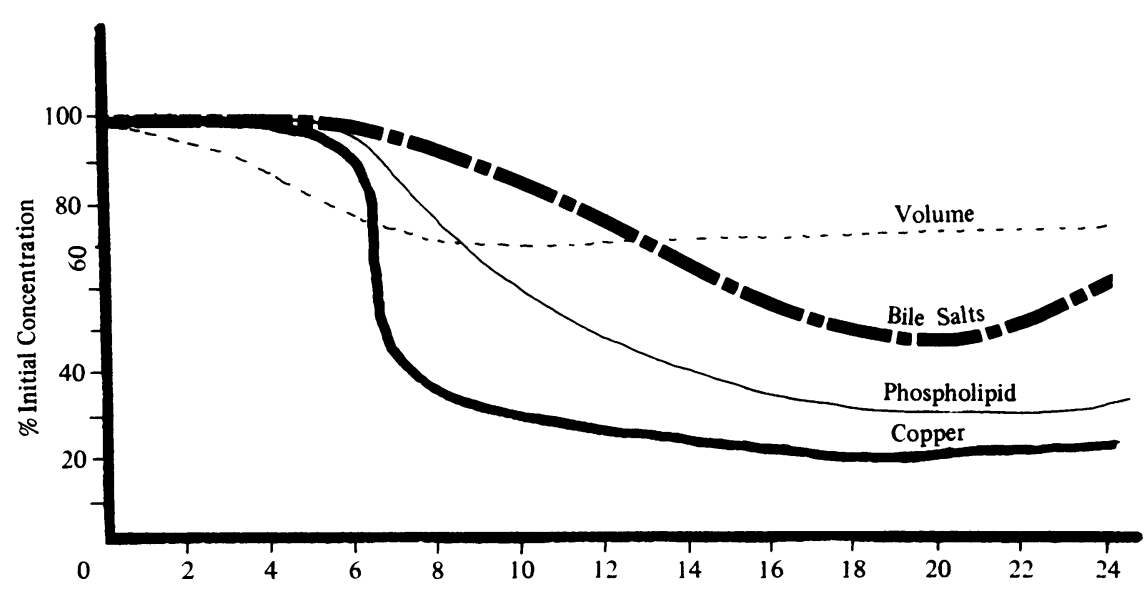

Fig. 3 Variation with time in the concentration of some of the constituents of human fistula bile. The concentrations and the volumes of bile are shown as percentages of the initial value for the 24-hr period following the fitting of a T-tube. 


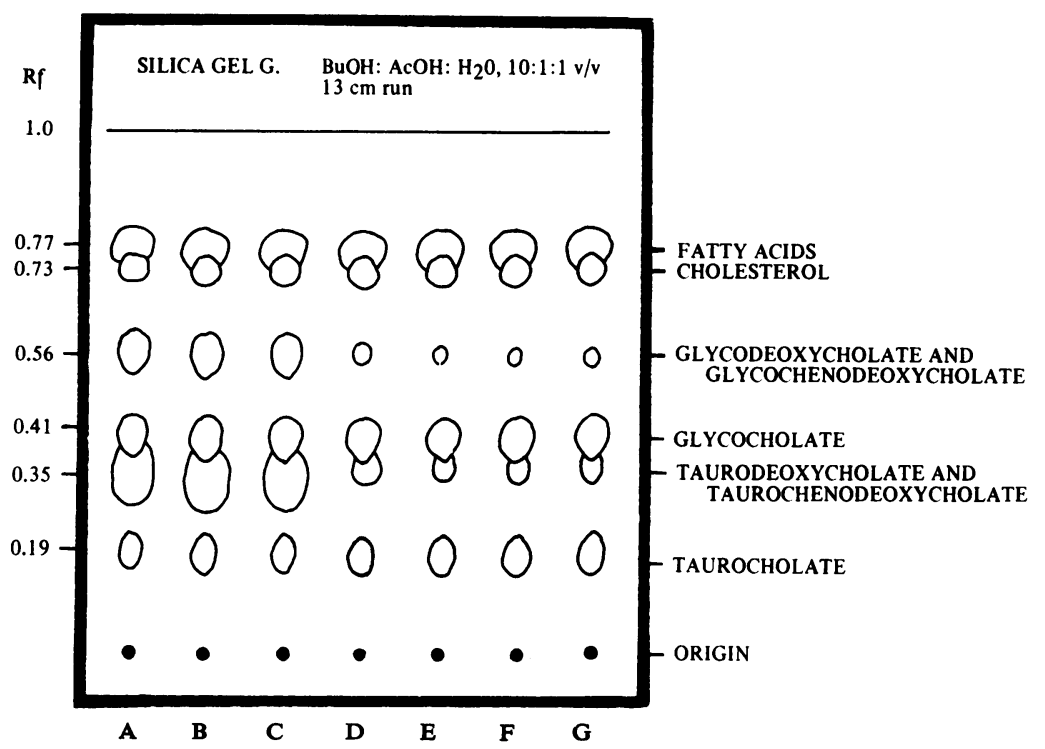

Fig. 4 Thin-layer chromatography of bile salts in T-tube bile. The fractions A to $\mathrm{G}$ were obtained at varying intervals after production of the fistula. Fractions $\mathrm{C}$ and D immediately precede and follow the time when biliary copper levels changed considerably. The chromatogram shows the reduction in the proportion of dihydroxy bile salts (both glycine and taurine conjugates) in the bile occurring at the time when biliary copper concentration falls.

\begin{tabular}{lll}
\hline Compound & $\begin{array}{l}\text { From Free } \\
\text { Salt }(\%)\end{array}$ & $\begin{array}{l}\text { From LBS } \\
\text { Complex }(\%)^{1}\end{array}$ \\
\hline Bile & - & 6 \\
Taurochenodeoxycholate & 7 & 7 \\
Glycocholate & 7 & 15 \\
Glycochenodeoxycholate & 35 & 50 \\
Taurodeoxycholate & 52 & 67 \\
Glycodeoxycholate & 78 & 78 \\
Taurocholate & 95 & 90 \\
Cholate & 7 & - \\
Chenodeoxycholate & 58 & - \\
Deoxycholate & 95 & - \\
\hline
\end{tabular}

Table V Extractability of copper from bile and from solutions of bile salts (free and as complexes with lecithin) after enrichment with $2.5 \mu \mathrm{g} \mathrm{Cu}^{2+}$ as sulphate ${ }^{1}$ Lecithin-bile salts complex

Electrophoresis of copper-enriched lecithin-bile-salt complexes containing specific bile salts

The association of copper with specific LBS complexes was examined by electrophoresis. A brown band containing lecithin moved in the agar gel and was allowed to migrate $50-60 \mathrm{~mm}$.

With taurocholate-lecithin complex (Fig 5a) the copper distribution was very similar to that obtained with the crude taurocholate experiment (Fig. 2e).

Glycocholate, glycodeoxycholate, and taurodeoxycholate complexes (Fig. 5b, c, d) gave similar results to the taurocholate complex.

Glycochenodeoxycholate complex (Fig. 5e) gave a copper distribution more in favour of the pigmented band. With taurochenodeoxycholate com- plex, however, the distribution of copper was strikingly different in that a much greater proportion of copper was associated with the LBS band.

In a direct comparison of taurochenodeoxycholate complex and human bile enriched with copper to the same level ( $1.0 \mu \mathrm{g} \mathrm{Cu} / \mathrm{mg}$ bile solids) a high degree of correspondence between the copper distributions was seen (Fig. 6).

Biliary copper in rats after intraduodenal administration of copper and bile salts

The rate of bile flow remained fairly constant with each animal throughout the period of each experiment but varied between animals.

Figures 7,8 and 9 show the variations in biliary copper concentration with time using different intraduodenal injections. Despite the variation in bile flow rates, the maximum biliary copper concentrations attained within each group of experiments were remarkably constant.

Injection of physiological saline gave no increase in copper excretion or biliary copper concentration. Injection of copper sulphate $(500 \mu \mathrm{g})$ in saline gave the results shown in Fig. 7 (represented in Figs. 8 and 9 as hatched areas).

Intraduodenal injection of human bile gave no increase in biliary copper concentration. Injection of human bile enriched with copper sulphate $(500 \mu \mathrm{g}$ $\mathrm{Cu})$ gave increases in both biliary copper concentrations and total copper excretions (Fig. 7). These increases agreed closely but differed from those 

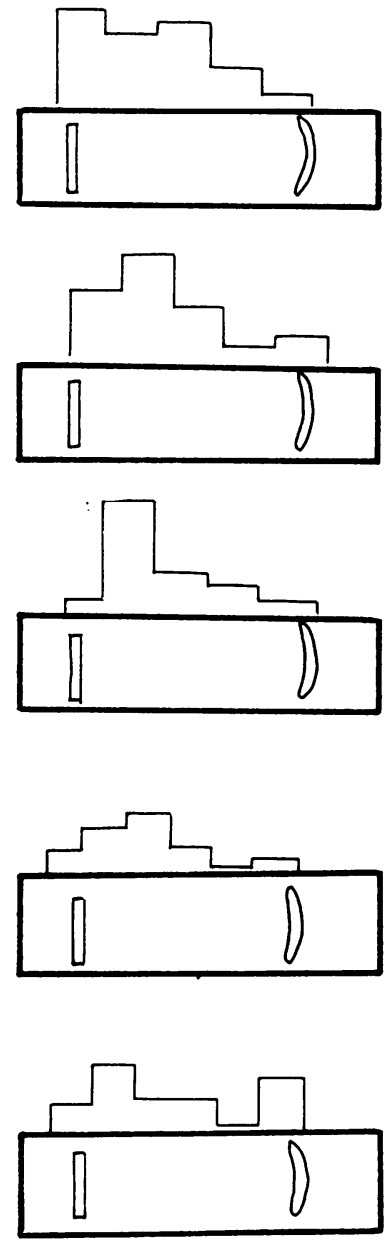

(e)

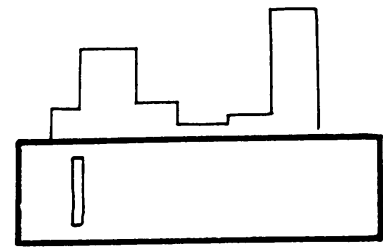

(b)

(c)

(a)
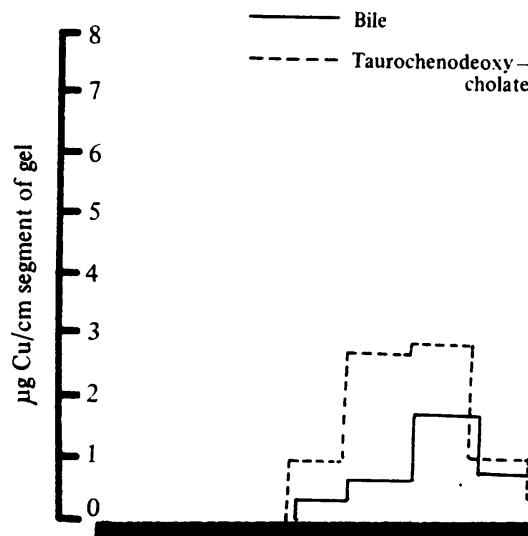

cholate
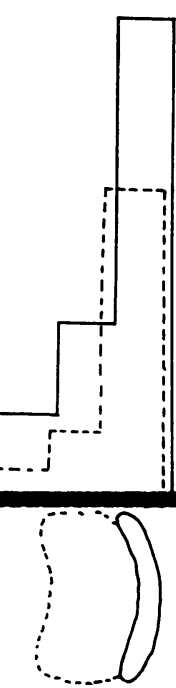

Fig. 6 obtained with copper in saline (shown in Figs. 8 and 9 as hatched areas).

Two experiments were performed with copperenriched lecithin-taurocholate complex in saline. The resulting biliary copper concentrations are shown in Figure 8. The values are intermediate between those of the copper + saline and copper + bile experiments. Similar results were obtained in two experiments with the lecithin-taurodeoxycholate complex (Fig. 8).

The taurochenodeoxycholate complex enriched with copper gave biliary copper concentrations that
Fig. 5 Agar gel electrophoresis of synthetic biles enriched with copper sulphate. The synthetic biles consist of specific bile salts with lecithin and cholesterol. The components were intimately mixed then dissolved in saline. The examples shown contain: (a) taurocholate; (b) glycocholate; (c) glycodeoxycholate; (d) taurodeoxycholate; (e) glycochenodeoxycholate; (f) taurochenodeoxycholate.

Fig. 6 Comparison of copper distribution after agar gel electrophoresis of bile and a synthetic mixture. The human bile was enriched with copper sulphate. The synthetic bile, containing taurochenodeoxycholate as sole bile salt, also had added copper sulphate.

were lower (Fig. 8), resembling the copper + bile experiments. In control experiments, LBS complexes gave no change in biliary copper eoncentration.

Experiments were also performed with lecithin complexes of glycine conjugates. On mixing lecithinglycochenodeoxycholate complex with copper sulphate in saline a flocculent precipitate was produced. This mixture, containing but little copper in solution, was administered intraduodenally. The biliary copper concentration was found to rise even higher than in the copper + saline experiment (Fig. 9).

With the lecithin-glycocholate complex aggre- 


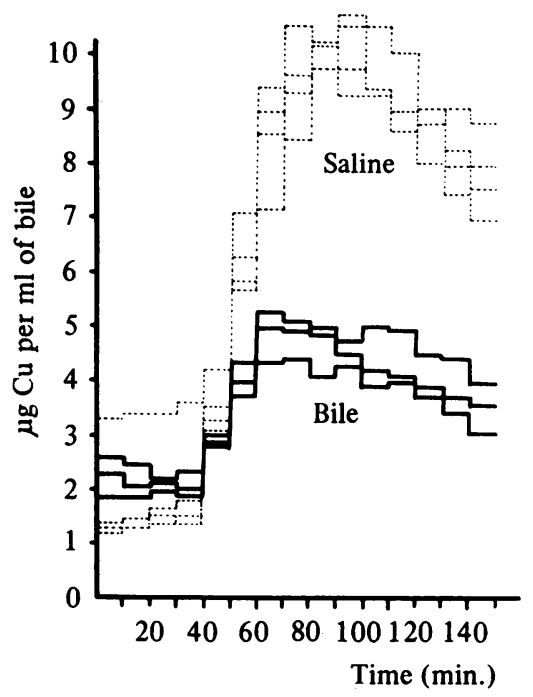

Fig. 7 Copper concentration in rat bile after administration of copper sulphate. An intraduodenal injection of $500 \mu \mathrm{g}$ of copper was given in either saline or bile exactly 30 minutes after cannulation of the bile duct.

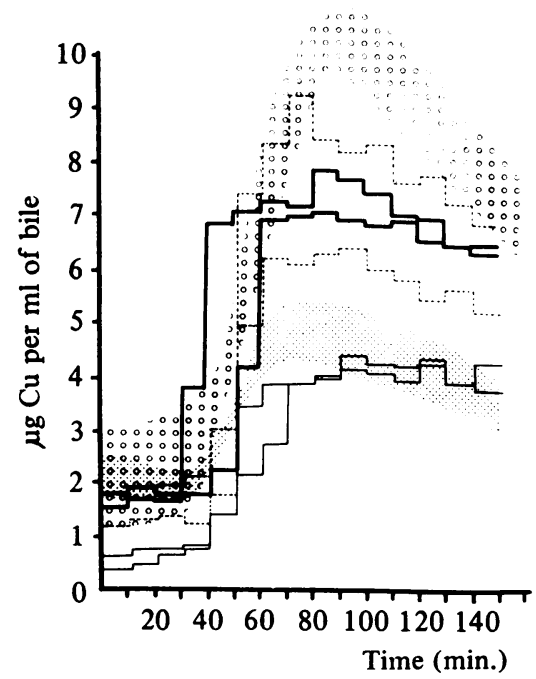

Fig. 8 Copper concentration in rat bile after administration of copper sulphate. An intraduodenal injection of $500 \mu \mathrm{g}$ of copper was given in each of three synthetic biles exactly 30 minutes after cannulation of the bile duct. The synthetic mixtures contained taurochenodeoxycholate as sole bile salt. - _- - Taurocholate; taurochenodeoxycholate; taurodeoxycholate.

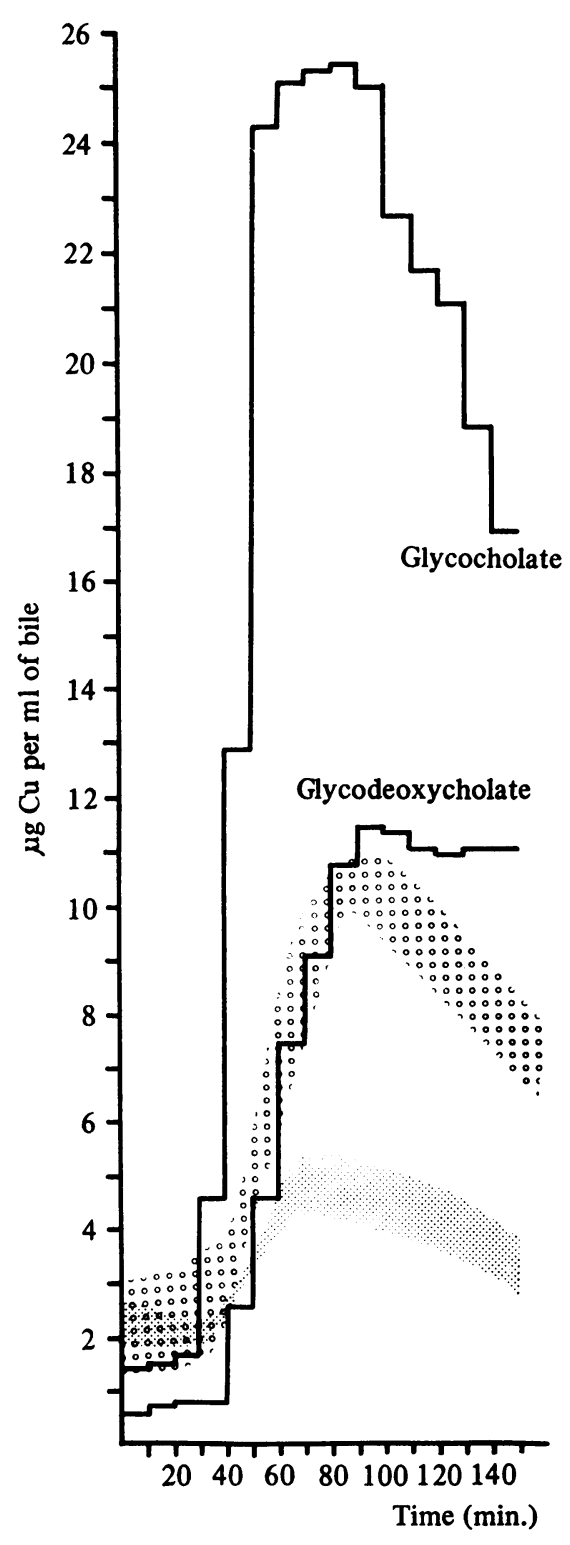

Fig. 9 Copper concentration in rat bile after administration of copper sulphate. An intraduodenal injection of $500 \mu \mathrm{g}$ of copper was given in a synthetic bile containing a specific glycine conjugated bile salt exactly 30 minutes after cannulation of the bile duct. 


\begin{tabular}{lcc}
\hline Intraduodenal Injection & $\begin{array}{l}\text { Absolute Copper } \\
\text { Excretion }\end{array}$ & $\begin{array}{c}\text { Percentage of } \\
\text { Average Saline } \\
\text { Value }\end{array}$ \\
& & $92 \cdot 5$ \\
& $10 \cdot 3$ & $100 \cdot 0$ \\
$\mathrm{Cu}^{2+}+$ saline & $11 \cdot 1$ & $92 \cdot 5$ \\
& $10 \cdot 3$ & $116 \cdot 0$ \\
& $12 \cdot 9$ & $46 \cdot 2$ \\
$\mathrm{Cu}^{2+}+$ bile & $5 \cdot 1$ & $51 \cdot 8$ \\
& $5 \cdot 8$ & $38 \cdot 6$ \\
$\mathrm{Cu}^{2+}+$ taurochenodeoxycholate & $4 \cdot 3$ & $36 \cdot 3$ \\
& $5 \cdot 3$ & $47 \cdot 6$ \\
$\mathrm{Cu}^{2+}+$ taurodeoxycholate & $8 \cdot 9$ & $80 \cdot 0$ \\
& $11 \cdot 1$ & $100 \cdot 0$ \\
$\mathrm{Cu}^{2+}+$ taurocholate & $6 \cdot 0$ & $53 \cdot 9$ \\
& $8 \cdot 0$ & $71 \cdot 7$ \\
$\mathrm{Cu}^{2+}+$ glycochenodeoxycholate & $15 \cdot 0$ & 135 \\
$\mathrm{Cu}^{2+}+$ glycocholate & $29 \cdot 6$ & 267 \\
\hline
\end{tabular}

Table VI Absolute biliary copper excretion in two hours following intraduodenal administration of $500 \mu \mathrm{g}$ of $\mathrm{Cu}^{2+}$ with saline, bile, or LBS-complexes ${ }^{1}$

${ }^{1}$ Lecithin-bile salt complexes

gation was prevented by increasing the proportion of lecithin in the complex by $40 \%$. This mixture resulted in a biliary copper concentration far in excess of those in the copper + saline experiment (Fig. 9). The results expressed as absolute copper excretions (Table VI) give the same picture as the concentration data.

THIN-LAYER CHROMATOGRAPHY STUDIES OF THE BILE SALT COMPOSITION OF DUODENAL JUICE FROM NORMAL SUBJECTS AND PATIENTS Duodenal juice from eight normal volunteers and two Wilson's disease patients was examined together with gallbladder bile from eight postmortem cases. One of the Wilson's disease patients was an asymptomatic girl of 12 years on penicillamine treatment and the other patient was a 30-year-old male with neurological symptoms for eight years but showing gradual improvement on penicillamine and potassium sulphide.

Separations were as in Figure 4. Considerable variations were seen in the ratio of glycocholate to taurine conjugates of the di- and tri-hydroxy bile acids, but the proportions of di- and tri-hydroxy taurine conjugates varied in unison from specimen to specimen. The major variation in bile salt patterns was due to the relative conjugation by glycine and taurine. Of the 18 specimens examined, those from the two Wilson's disease patients had the lowest taurine/ glycine $(T / G)$ ratios. These patients' $T / G$ ratios were not widely different from the ratios seen in some normal specimens, but they clearly fell at the extreme lower limit of normal.

Following alkaline hydrolysis, it was seen that the proportion of deoxycholic acid was increased above normal in the Wilson's disease specimens and that the proportion of cholesterol was greatly reduced in one patient.

\section{Discussion}

The main technique used for fractionating bile components was agar gel electrophoresis as this method was unlikely to cause changes in the distribution of copper between the constituents of bile. Previous electrophoretic studies on bile have demonstrated the presence of albumin and two fractions migrating faster than albumin (Schultze and Heremans, 1966). These fractions are micellar in nature, comprising bile salts and most of the phospholipid, cholesterol, and bile pigments of bile (Desai, Glover, and Joo, 1965; Norman, 1965). Lecithin and bile salts form stable complexes (Isaksson, 1954) and they produce the mixed micelles that solubilize cholesterol and other lipophilic constituents of bile (Bourges, Small, and Dervichian, 1967). Immunoelectrophoresis has demonstrated the variable presence of serum $\alpha_{1}$-glycoprotein, $\alpha_{2}$ haptoglobin, transferrin, $\gamma$-globulins, and three bile specific proteins (Yoon, Shim, and Kil, 1966) but there are no proteins in the fast moving micellar fractions (Clausen, 1962; Desai et al, 1965). Most of the copper has been shown here to be present in the micellar fractions (Fig. 2a). The substantial proportion of biliary copper extractable into chloroform from lyophilized bile (Table I) further suggests that copper is not bound to macromolecular species, such as protein or polysaccharide, but is complexed with constituents of low molecular weight. The variation in the pattern of copper extraction is attributed to a variable solubilization effect of other bile constituents present in different quantities.

The nature of the biliary copper complex is such that it migrates on electrophoresis of $p \mathrm{H} 6.0$ towards the anode, is not precipitable by phosphate, and cannot be detected by the electrolytic AAS technique. The material binding copper in bile is present in great excess since the migratory behaviour of copper is unchanged after adding even a hundred-fold increase in cupric ions (Fig. 2c). The fast anodic migration of the copper at $p \mathrm{H} 6.0$ shows that the copper is bound to some substance present in large quantities in bile and that the copper complex becomes soluble in the biliary micellar phase. Copper ions added to bile probably form the same complexes as copper excreted into bile by the liver, because other workers report that in widely different experiments results were independent of whether labelling with ${ }^{64} \mathrm{Cu}$ was effected by the direct addition of copper ions to bile, or by collection of the bile after the administration of ${ }^{64} \mathrm{Cu}$ to intact animals (Frommer, 1971; Owen, 1964). 
Information concerning the physiological biliary copper complexing agent was provided by the solvent fractionation of extracts of lyophilized bile. Solvent fractionation of a chloroform extract gave a coppercontaining product which consisted largely of LBS complex. The copper was bound directly to the LBS complex rather than to an unknown lipophilic material solubilized in the LBS complex, because the ether-soluble LBS complex was rendered insoluble by the action of phospholipase $\mathrm{A}$, when the copper, previously soluble in ether, was then found to be insoluble.

Solvent fractionation of the methanol-chloroform extract gave a colourless copper product which consisted solely of inorganic salts of conjugated bile acids.

The series of boiling solvents caused some randomization of the copper; inorganic copper in the methanol extract was not present in bile because during electrophoresis it would have precipitated at the origin. Similarly, copper was found associated with protein, whereas none was found so complexed in the electrophoresis experiments.

As most copper was extracted in association with bile salts and lecithin-bile salts, and had micellar associations during electrophoresis, it was tentatively concluded that biliary copper was complexed with bile salts. The absence of 'cationic' copper, even after the addition of cupric ions to bile was reproduced by an aqueous solution of sodium taurocholate with the electrolytic AAS technique. Similarly, the capacity of bile in yielding poor recoveries of copper by chelation-extraction methods was reproduced by aqueous solutions of sodium glycocholate or taurochenodeoxycholate (Table V).

Additional evidence to these physico-chemical considerations was desirable for proof of the association between biliary copper and bile salts and so evidence was sought for a metabolic relationship between these materials. Because output of bile salts into bile is high and the synthesis rate low de novo, biliary levels are maintained by an active enterohepatic circulation. Production of an external fistula causes biliary concentrations of bile salts to fall after several hours due to depletion of the body pool (Eriksson, 1957; Dowling, Mack, Picott, Berger, and Small, 1968). Over a 24-hr period in a cholecystectomy patient fitted with a $\mathrm{T}$ tube, a remarkable correlation between copper concentration and dihydroxy bile salt concentration was observed. This result demonstrates that copper excretion is dependent upon the excretion of the dihydroxy bile salts.

The concentrations of the glycine and taurine dihydroxy bile acid conjugates changed in unison (Fig. 4) due to depletion of dihydroxy bile acids. This result posed the question as to whether it was the glycine and/or the taurine conjugates which were implicated in copper excretion. This question was pursued by further electrophoretic studies and it was found that taurochenodeoxycholate was by far the superior bile salt in effecting migration of copper with the micellar fraction (Fig. 5). Complex formation with lecithin is necessary for electrophoretic migration of copper and so biliary copper is probably associated with the taurochenodeoxycholatelecithin complex.

Recent work on the copper-binding capacity of bile (Gollan, Davis, and Deller, 1971) showed that serial dilution of gallbladder bile had little effect on its binding capacity until a critical point was reached, after which there resulted a rapid nonlinear decline in the copper-binding capacity. This behaviour is consistent with the dissolution of biliary micelles with increasing dilution.

Due to its enterohepatic circulation, the effect of bile and LBS complexes on intestinal absorption of copper is relevant to a study of Wilson's disease. In the studies involving intraduodenal administration of copper, fairly high doses were required to obtain measurable increases in biliary copper, but, as these doses were still within the linear range of the relationship between oral copper dose and 'theoretic absorption' (Owen, 1964), the normal processes of absorption were still operating. Owen (1964) showed the validity of biliary copper levels as an index of copper absorption, taking cognizance that this relationship is not linear.

Taurochenodeoxycholate may control the absorption of copper in the upper intestine because it produced effects on copper absorption which were very similar to those of bile, in contrast to other taurine conjugates which produced much smaller effects. The increased absorption of copper from the copper-glycine conjugates occurs because they are weakly ionized substances and are therefore readily absorbed. Glycine conjugates themselves are more completely re-absorbed in the upper intestine than taurine conjugates because the latter do not form weakly ionized species at body $p \mathrm{H}$. The taurine conjugates reaching the lower intestine are subjected to bacterial deconjugation and the free bile acids are absorbed there.

The mechanism of copper excretion might then involve complexing of copper with taurochenodeoxycholate in the liver, thereby preventing its reabsorption from the upper intestine, with subsequent splitting of the complex in the lower intestine at a site which allows only reabsorption of the bile acid. Support for this role of taurochenodeoxycholate is the finding that pyridoxine deficiency in rats causes a rise in body copper (Gubler, Cartwright, and Wintrobe, 1949) and also an increase in 
biliary glycine conjugation at the expense of the taurine conjugates (Bergeret and Chatagner, 1952). The low $T / G$ ratios in the two Wilson's disease patients are in line with the hypothesis that the increased levels of copper are due to the reabsorption of biliary copper.

The data, ie, ratio of conjugates, do not indicate whether the bile salt pattern in the Wilson's disease patients is due to increased glycine or decreased taurine conjugate production and, unfortunately, the information regarding absolute production rates was not accessible.

The data support also an alternative, but not necessarily exclusive, hypothesis that the production of taurochenodeoxycholate is necessary for mobilization of copper from the tissues into bile and that where production is limited there is accumulation of copper.

The metabolic significance of the increased proportion of deoxycholate is not clear, but may be indicative of an abnormal gut flora or a reduced catabolism by the diseased liver. It is to be noted that the increased proportion of deoxycholate in the patients' duodenal juice would mask an even greater reduction in the proportion of the important taurochenodeoxycholate that had been judged to be present on the chromatograms since these taurine conjugates were not separated on the tlc system used.

In the event that reduced proportions of taurochenodeoxycholate are observed in a larger series of Wilson's disease patients, a rational therapy would appear to be the administration of this bile salt in encapsulated form for liberation in the duodenum.

The author wishes to express his gratitude to Professor G. H. Lathe for advice and discussion and to acknowledge the financial help given by the Medical Research Council and the Wellcome Trust. Thanks are also due to Mrs J. Joyce for technical assistance and to Mr G. Divall who carried out a section of the animal experiments as an undergraduate project.

\section{References}

Bergeret, B., and Chatagner, F. (1952). Désulfinication et décarboxylation enzymatiques de l'acide L-cystine sulfinique: sa transformation quantitative en alanine et en hypotaurine. Biochim. biophys. Acta (Amst.), 9, 141-146.
Bergström, S., and Sjövall, J. (1954). Occurrence and metabolism of chenodeoxycholic acid in the rat. Bile acids and steroids 13 . Acta chem. scand., 8, 611-616.

Bourges, M., Small, D. M., and Dervichian, D. G. (1967). Biophysics of lipid associations. III. The quaternary systems lecithin-bile salt-cholesterol-water. Biochim. biophys. Acta (Amst)., 144, 189-201.

Clausen, J. (1962). Proteins and acid mucopolysaccharides in the bile. Protides biol. Fluids, 10, 211-217.

Connerty, H. V., Briggs, A. R., and Eaton, E. H., Jr. (1961). Simplified determination of the lipid components of blood serum. Clin. Chem., 7, 37-53.

Dawson, J. B., and Ellis, D. J. (1970). Unpublished results.

Desai, J. C., Glover, J., and Joo, C. N. (1965). The form of dispersion of sterols in bile and plasma. In The Biliary System, edited by W. Taylor, pp. 145-164. Blackwell, Oxford.

Dowling, R. H., Mack, E., Picott, J., Berger, J., and Small, D. M. (1968). Experimental model for the study of the enterohepatic circulation of bile in Rhesus monkeys. J. Lab. clin. Med., 72, 169-176.

Eriksson, S. (1957). Biliary excretion of bile acids and cholesterol in bile fistula rats. Bile acids and steroids. Proc. Soc. exp. Biol. (N.Y.), 94, 578-582.

Farrer, P. A., and Mistilis, S. P. (1968). Copper metabolism in the rat: studies of the biliary excretion and intestinal absorption of "Cu-labeled copper. Wilson's Disease, edited by D. Bergsma, pp. 14-22. (Birth Defects Original Article Series, Vol. IV, no. 2). National Foundation-March of Dimes.

Frommer, D. (1971). The binding of copper by bile and serum. Clin. Sci., 41, 485-493.

Gollan, J. L., Davis, P. S., and Deller, D. J. (1971). A radiometric assay of copper binding in biological fluids and its application to alimentary secretions in normal subjects and Wilson's disease. Clin. chim. Acta, 31, 197-204.

Gubler, C. J., Cartwright, C. E., and Wintrobe, M. M. (1949). Effect of pyridoxine deficiency on the absorption of iron by the rat. J. biol. Chem., 178, 989-996.

Isaksson, B. (1965). On the lipids and bile acids in normal and pathological bladder bile. Thesis, Gothenburg University.

Norman, A. (1965). Physico-chemical properties of bile constituents. In The Biliary System, edited by W. Taylor, pp. 165-174. Blackwell, Oxford.

Owen, C. A., Jr. (1964). Absorption and excretion of $\mathrm{cu}^{\text {s4 }}$-labeled copper by the rat. Amer. J. Physiol., 207, 1203-1206.

Peters, Sir R. A. (1966). A study of the toxic action of copper on brain tissue in vivo and in vitro. In The Biochemistry of Copper, edited by M. Peisach, P. Aisen, and W. E. Blumberg, pp. 175181. Academic Press, New York and London.

Schultze, H. E., and Heremans, J. F. (1966). Proteins of digestive secretions. Molec. Biol. hum. Proteins, 1, 802-808.

Stoner, R. E., and Dasler, W. (1960). Detection of copper following extraction with 1,5-diphenylcarbohydraxide in benzene. Analyt. Chem., 32, 1207-1208.

Walker, B. E., Dawson, J. B., and Ellis, D. J. (1969). In Atomic Absorption Spectroscopy (Proceedings of the 2nd International Conference, Sheffield, 1969), edited by R. M. Dagnall and G. F. Kirkbright. Butterworths, London. (Also Pure appl. Chem., 2 3(1)).

Weinbren, K., and Billing, B. H. (1956). Hepatic clearance of bilirubin as an index of cellular function in the regenerating rat liver. Brit. J. exp. Path., 37, 199-204.

Wheeler, H. O., and Ramos, O. L. (1960). Determination of the flow and composition of bile in the unanaesthetised dog during constant infusions of sodium taurocholate. J. clin. Invest., 39, 161-170.

Yoon, D. S., Shim, B. S., and Kil, T. S. (1966). Bile specific protein components in human hepatic bile. J. Lab. clin. Med., 67, 640-649. 